\title{
REFLEXIONES SOBRE EL CONCEPTO DE GUERRA CIVIL
}

\author{
POR
}

EdUARDo GONZÁLEZ CALLEJA

\section{RESUMEN - ABSTRACT}

El artículo describe el fenómeno de la guerra como un conflicto armado de máxima intensidad. Estudia su caracterización jurídica, la peculiar relación dialéctica que se establece entre el estado de guerra y el de paz, y la etiología, características y efectos de la guerra civil como conflicto político en gran escala dirigido a la conservación o conquista del poder estatal.

This article shows the phenomenon of war as the highest intensity point in an armed conflict. The work looks over his juridical typification, the special dialectical relation established between situations of war and peace, and the ethiology, characteristics and consequences of civil war as a big scale political conflict whose aim is the preservation or conquest of state power.

\section{PALABRAS CLAVE - KEY WORDS}

Teoría política. Conflicto. Violencia. Guerra Civil.

Political theory. Conflict. Violence. Civil War.

En la tipología de los hechos violentos, la guerra aparece como la máxima expresión posible de una confrontación armada, tanto por la entidad de los actores colectivos que intervienen (desde Estados o coaliciones de Estados hasta grandes instituciones y organizaciones o vastos grupos sociales), como por la cuantía y calidad de los recursos desplegados (desde el grado de apoyo social e institucional al control de recursos materiales como dinero y armamento, o recursos de influencia como la movilización de combatientes, las alianzas con fuerzas interiores o exteriores o el control de los espacios clave del poder político), y por la trascendencia de los objetivos que persigue, que son la conquista total del Estado, la transformación profunda de las reglas del juego político o la realización de cambios sustanciales en la organización social en su conjunto. En tanto que arquetipo de la cultura de la violencia y como forma límite de resolución de conflictos por vía armada ${ }^{1}$, la guerra es «una especie de género de violencia colectiva, directa, manifiesta, personal, intencional, organizada, institucionalizada, instrumental, sancionada, y a veces ritualizada y regulada» ${ }^{2}$; un conflicto

1 Julio ARÓSTEGUI, «La guerra (el mal de las armas desde nuestra época)», Salamanca, Revista de Estudios, ${ }^{\circ}$ 40, 1997, p. 17.

2 Hans VAN DER DENNEN, «Sobre la guerra: conceptos, definiciones, datos de investigación. Un breve examen de la literatura y la bibliografía existentes», en UNESCO, Anuario de estudios sobre Paz y Conflictos, Barcelona, Ed. Fontamara, 1986, vol. I, p. 116. 
armado entre grupos de población que podían ser entendidos, en su sentido más amplio, como «unidades orgánicas, como razas o tribus. Estados o unidades geográficas menores, partidos religiosos o políticos, clases económicas» ${ }^{3}$.

La primera preocupación teórica respecto del hecho bélico estuvo vinculada a la constatación de su peculiar status legal en el contexto del Derecho de Gentes. Para los juristas de los siglos XVIII y XIX, herederos doctrinales de Hugo Grocio, autor de De Jure belli ac pacis libri tres (Droit de la Guerre et de la Paix, París, 1613), la guerra era, simplemente, una institución que permitía ciertos tipos de comportamiento y de acción calificados por el Derecho como inadecuados para un estado de paz. La guerra era un medio de resolver diferencias entre dos o más entidades políticas soberanas, es decir, Estados nacionales o unidades de población (tribus, feudos, imperios, ciudades-Estado, etc.) capaces de recurrir a fuerzas militares organizadas como instrumento para zanjar sus disputas. De modo que la principal característica de un estado de guerra era la igualdad jurídica de los beligerantes, su libertad para utilizar la fuerza armada contra sus rivales, y la necesaria imparcialidad o al menos la cauta abstención de los espectadores. En ese sentido, el polemólogo Quincy Wright caracterizó la guerra como «la condición legal que permite por igual a dos o más grupos hostiles llevar a cabo un conflicto mediante fuerzas armadas» 4 , y como "un conflicto entre grupos políticos, especialmente entre Estados soberanos, conducido por importantes contingentes de fuerzas armadas durante un período de tiempo considerable» ${ }^{5}$. La guerra es, por tanto y simultáneamente, un estado jurídico y una forma de conflicto, que implica un cierto grado de igualdad legal, de hostilidad y de violencia en las relaciones entre los grupos contendientes. En definitiva, la guerra ha de someterse a ciertas reglas de procedimiento y gestión al institucionalizarse como conflicto armado de máxima intensidad ${ }^{6}$.

La peculiar relación entre la guerra y la paz ha sido otro aspecto muy debatido en el campo de la filosofía política, desde el momento en que algunos autores han advertido que no son conceptos antagónicos, sino que su base común es la búsqueda del poder, lo que convierte a la guerra y la paz en partes inseparables de una misma actividad política. Como señala Schwartzenberger, "en un sistema de política de poder, no hay diferencia entre la paz y la guerra» ${ }^{7}$. Si la guerra es "un enfrentamiento armado entre dos o más instituciones soberanas que emplean fuerzas militares organizadas en la persecución de fines específicos», es decir, un conflicto agudo organizado, unificado y concentrado en la periferia del hábitat de una sociedad, la paz es la agregación de conflictos internos crónicos, difusos y no organizados, que no degeneran en un enfrentamiento abierto y armado a gran escala ${ }^{8}$. De suerte que la guerra y la paz forman los extremos de un continuum de actitudes enfocadas a la resolución de los conflictos. Barringer considera que la guerra es «un posible modo de actividad política orientada a resolver eficaz y favorablemente un determinado conflicto de intereses. En este sentido, la guerra es solamente una de las muchas formas de resolución de conflicto, siendo otras la negociación, la conciliación, el arbitraje y la adjudicación. Es solamente un subconjunto particular del conjunto más amplio de todos los modos de conflicto, que abarca todas las situaciones socialmente (si no jurídicamente) reconocidas en las que tienen lugar

3 Alvin JOHnSON, «War», en E.R. SELIGMAN (dir.), Encyclopaedia of the Social Sciences, Nueva York, MacMillan, 1937, vol. XV, p. 331

4 Quincy WrIGHT, A Study of War, 2a ed. Chicago, University of Chicago Press, 1965, pp. 8 y 698.

5 Quincy WRIGHT, «Guerra», en David L. SILLS (dir.), Enciclopedia Internacional de las Ciencias Sociales, Madrid, Aguilar, 1975, vol. V, p. 257.

6 Gernot KöHLER, «Aproximaciones al estudio de las causas de la guerra», en UNESCO, Anuario de estudios sobre Paz y Conflictos, Barcelona, Ed. Fontamara, 1986, vol. I, pp. 126-127.

7 G. SChWARTZENBERGER, «Peace and War in International Society», International Social Science Bulletin (París), vol. II, n 3, 1950, pp. 336-347.

8 H. KALLEN, «Of War and Peace», Social Research (Nueva York), n 23, IX-1939, p. 373. 
hostilidades armadas de considerable magnitud sobre una base sistemática y continua por parte de las fuerzas armadas de dos o más facciones políticas, organizaciones, naciones, gobiernos o Estados. Dado que el término "guerra" comporta implicaciones y connotaciones jurídicas que ningún organismo político admite públicamente sufrir o arriesgar, la situación de guerra «de facto» será designada como de "hostilidades" "9.

Excepto por su rasgo común de violencia organizada de gran magnitud, las guerras han diferido radicalmente en su origen, etiología y efectos, y las concepciones teóricas sobre las mismas también han sufrido grandes cambios ${ }^{10}$. Deutsch y Sengaas describen la guerra como «violencia organizada real a gran escala, preparada y mantenida por la compulsión y las proclamaciones de legitimidad de un Estado y su gobierno, y dirigida contra otro Estado o cuasi-Estado, es decir, una organización política relativamente comparable» ${ }^{11}$. Por su parte, Gaston Bouthoul la definió de forma excesivamente vaga y genérica como «lucha armada y sangrienta entre agrupaciones organizadas ${ }^{12}$. En efecto, la maximización de la organización intensiva y extensiva de la violencia, la equiparación de iure y de facto entre los contendientes y los esfuerzos de legitimación de la actividad político-militar son aspiraciones siempre presentes en los protagonistas de los conflictos bélicos.

Waldmann y Reinares aplican el término guerra a un conflicto violento que reuniría varias características fundamentales: 1) un conflicto manifiesto de considerable magnitud (es decir, con muchas personas involucradas y una elevada tasa de víctimas mortales); 2) un enfrentamiento entre dos o más bandos militares que mantienen un equilibrio mínimo de fuerzas, y uno de los cuales al menos combate en nombre de la autoridad establecida; 3) una mínima organización centralizada de la lucha y de los combatientes, y 4) una cierta coordinación y planificación de las acciones militares en ambos bandos, con cargo a una estrategia global de lucha ${ }^{13}$. Soberanía en disputa, organización extensa e intensa de la violencia y amplia duración serían las características esenciales de la guerra como arquetipo de conflicto político.

Como fenómeno integrado en la más amplia tipología del hecho bélico, en la guerra civil se dan los rasgos más sobresalientes de una guerra convencional, aunque no siempre de forma perfecta, ya que a veces el Estado se encuentra en proceso de disolución (con el consiguiente riesgo de aparición de ejércitos privados y «señores de la guerra»), y el enfrentamiento de mayor intensidad no se produce necesariamente entre grupos armados perfectamente organizados para la lucha, sino entre éstos y la población civil, como sucede con demasiada frecuencia en las eufemísticamente denominadas low intensity wars. De modo que estos autores definen arquetipos bélicos a menudo interrelacionados: guerras contra el propio régimen con el objetivo de un profundo cambio socioeconómico, guerras de secesión o auto-

9 Richard E. BARringer, War: Patterns of Conflict, Cambridge (Mass.), MIT Press, 1972, pp. 12-13.

10 Según KÖHLER, «Aproximaciones al estudio de las causas de la guerra», p. 106, en las investigaciones contemporáneas sobre la guerra hay dos tendencias principales: la investigación norteamericana hace hincapié en los factores estructurales y en los procesos anónimos, mientras que los estudiosos europeos occidentales ponen más acento en los actores y en sus propósitos. Entre los representantes de la «escuela anglosajona» destacan Lewis Richardson, Quincy Wright, Kenneth Waltz y Kennet E. Boulding. Los máximos representantes de la «escuela europea» serían Raymond Aron, André Beaufre, A.H. Jomini y los especialistas integrados desde 1945 en el Institut Français de Polémologie: Gaston Bouthoul, Reré Carrère o Jean Guitton. Pierre Joxe, un destacado representante de esta última tendencia designa con el término de estratégica al enfoque heurístico que vincula al conjunto de ciencias sociales que se dedican a la comprensión y explicación del fenómeno de la guerra, entendido como un arte que busca vencer la voluntad colectiva adversa mediante la amenaza de muerte a través de las armas o el hambre (Alain JOXE, La ciencia de la guerra y la paz, México, UNAM, 1998, pp. 9, 11 y 14).

11 Karl W. DEUTSCH y Dieter SENGAAS, «A Framework for a Theory of War and Peace», en Albert LEPAWSKY, Edward H. BuEHRIG y Harold D. LASSWELL (eds.), The Search for World Order. Studies by Students and Colleagues of QuincyWright, Nueva York, Appleton-Century-Crofts,1971, pp. 114-138.

12 Gaston Bouthoul, Tratado de Polemología, Madrid, Eds. Ejército, 1984, p. 103.

13 «Introducción» y Peter WALDMANN, «Guerra civil: aproximación a un concepto difícil de formular», en Peter WALDMANn y Fernando REINARES (comps.), Sociedades en guerra civil. Conflictos violentos de Europa y América Latina, Barcelona, Paidós, 1999, p. 13 y 28 
nomistas, guerras internacionales entre estados por una posición de predominio y guerras de descolonización ${ }^{14}$.

La esencia de la naturaleza histórico-política de la guerra civil no radica en sus manifestaciones violentas - por lo demás, enormemente heterogéneas-, sino en su carácter de conflicto político en gran escala, de lucha en máximo grado para conservar o conquistar el poder de un Estado. Como advierte Charles Zorgbibe en su estudio histórico-jurídico sobre el tema, «el criterio de la guerra civil no reside en el carácter de las hostilidades: puede revestir la forma de operaciones militares clásicas o la más fluida de una guerra de guerrillas; ni en la naturaleza de las partes que se enfrentan: puede enfrentar facciones políticas o clases sociales, etnias o grupos religiosos; ni en el propio móvil del conflicto: puede estar en juego el régimen político de un Estado existente o la creación, por secesión, de un nuevo Estado». Aunque acto seguido reconoce que estos elementos (la magnitud de la violencia, de los contendientes y de los objetivos políticos que persiguen) distinguen a la guerra civil de otras turbulencias internas menores, que son revueltas localizadas en el espacio, limitadas en el tiempo y cuyos autores parecen querer impulsar el desorden sin previa concertación, y con objetivos aún imprecisos ${ }^{15}$. Pero — repitámoslo- la verdadera trascendencia de una guerra civil reside en la pretensión de dar solución a una crisis política marcada por la aguda polarización, la marcada hostilidad entre las fuerzas enemigas y la gran entidad de los recursos coactivos movilizados para solventarla.

El conflicto interno agudo ha sido interpretado como la desembocadura de una presión continuada o de una compulsión de breve duración. De acuerdo con esta línea de argumentación, el antagonismo aparece cuando persisten la injusticia o la desigualdad, y el gobierno impone medidas restrictivas o discriminatorias, sin poner en práctica ninguna política de consenso. Otra hipótesis parte del supuesto de que la protesta puede emprender una escalada hacia la guerra intestina como resultado de una fuerte represión gubernamental, ya que el aumento de la coerción no ofrece probabilidades o garantías de un reforzamiento del orden público, sino que, por el contrario, tiende a minarlo ${ }^{16}$. Un conflicto civil precisa para su desarrollo de la existencia de una verdadera situación prerrevolucionaria, caracterizada por un intenso grado de descontento que afecta a amplias capas de la sociedad por muy distintas razones: crisis económica, ruptura de la organización y normas de una comunidad, incapacidad manifiesta del gobierno para mantener el orden social o poner remedio a la situación de crisis, tentativas de secesión, derrota militar a manos de otro país, etc., etc. Ted R. Gurr considera que una crisis de este tipo puede derivar en guerra interna cuando el descontento o la privación relativa que afectan a la élite y a las masas son intensos y comprenden un gran número de bienes o valores; si la clase dirigente es particularmente ineficaz, y si existen grandes facilidades para emprender una acción violenta a gran escala ${ }^{17}$. Si se da este cúmulo de circunstancias, los disidentes podrían tratar de controlar el liderazgo de grandes organizaciones sociales y políticas, y adquirir la capacidad militar que haga posible la acción armada. Cuando se ocluyen los canales pacíficos (como los procesos electorales o las negociaciones y las mediaciones) para llegar a un acuerdo en los contenciosos planteados, y ninguna de las partes está dispuesta a reconocer un resultado adverso, la tensión se incrementa en un proceso cíclico y espiral de animosidad creciente. Basta entonces un acontecimiento puntual (crisis política, conspiración, atentado, insurrección, revolución) para precipitar o justificar la crisis violenta, que deriva en conflicto militar cuando la coalición revolucionaria ha logrado acopiar un nivel de recursos equiparable al del gobierno, y ha conseguido organizar un con-

\footnotetext{
14 «Introducción» a WALDMANN y REINARES, Sociedades en guerra civil, p. 15.

15 Charles ZORGBIBE, La guerra civil, Barcelona, DOPESA, 1975, p. 8.

16 Walter LaQueUR, Terrorismo, Madrid, Espasa-Calpe, 1980, p. 14.

17 Ted Robert GURR, Why Men Rebel, $3^{\mathrm{a}}$ reimpr., Princeton, Princeton University Press, 1971, p. 342.
} 
trapoder que puede disputar la hegemonía y la legitimidad al propio Estado. Durante el curso de la lucha, los grupos sociales quedan enajenados dentro de la misma comunidad, y hasta los grupos menores (familias, redes de amistad y afinidad, comunidades, etc.) aparecen divididos.

En todo caso, la guerra civil se origina en un contexto de grave enfrentamiento doméstico, que puede adquirir una impronta religiosa (como las guerras europeas entre católicos y protestantes de 1550 a 1649, o la guerra «cristera» que asoló México entre 1926 y 1929), político-ideológica (como la guerra civil inglesa de 1641 a 1651, la guerra de secesión norteamericana de 1861 a 1865 o la guerra civil española de 1936-1939), social (como las guerras campesinas alemanas del siglo XVI, la rebelión zapatista de 1911-1919 o la guerra civil rusa de 1918-1921), étnica (como la que sacudió la ex-Yugoslavia entre 1991 y 1995) o de otro tipo, aunque las más cruentas y duraderas presentan un combinado muy diverso de fracturas internas. Este es, por ejemplo, el caso de las guerras de liberación nacional, donde entran en juego componentes violentos de carácter patriótico (lucha contra el dominio extranjero), socioeconómico (conflictos de clase), político (lucha partidista por el control del Estado), cultural (reivindicación de la identidad autóctona y denuncia del proceso «civilizador» de la potencia colonial), etc.

Excepto por el rasgo comun de la violencia organizada en gran escala, las guerras civiles han diferido radicalmente en la historia en su origen, etiología y efectos. En sus diversas modalidades de conflicto social, de guerra subversiva, de combate por la liberación nacional, etc., la guerra civil es un importante instrumento de cambio sociopolítico, que implica un modelo de violencia altamente organizada por una minoría, pero con una fuerte movilización y participación populares. En contraste con la revolución, la guerra civil no implica en sí misma un cambio radical de estructuras, aunque durante su desarrollo puedan manifestarse procesos revolucionarios o contrarrevolucionarios mejor o peor caracterizados. Como manifestación de un conflicto agudo, más o menos organizado, unificado y concentrado, y como tipo de violencia política máxima, la guerra civil se caracteriza por su carácter de movilización masiva de recursos materiales y humanos, por la amplitud bélica de las operaciones y por la duración de la acción. Suele adoptar la fisonomía de una lucha armada generalizada, bajo los parámetros de una guerra clásica, lo que no impide que estén presentes otras modalidades conflictivas muy diversas, como revoluciones, contrarrevoluciones, movimientos secesionistas o independentistas, enfrentamientos étnicos o religiosos, etc. Harry Eckstein engloba diversas manifestaciones violentas bajo la categoría de «guerra interna», que define como «todo intento de cambio, por la violencia o la amenaza de la violencia, de la política, titulares $u$ organización de un gobierno» ${ }^{18}$. La guerra interna implica a fuerzas sociales con actitudes bélicas para propósitos de competición política, y trastorna gravemente las normas políticas establecidas. Para Janos, guerra interna es «un conflicto violento entre partidos sujetos a una autoridad común, y de tales dimensiones que su incidencia afecta al ejercicio o estructura de autoridad en la sociedad» ${ }^{19}$. Por lo tanto, incluye una variada gama de fenómenos, desde los motines a las guerras civiles, pero excluye incidentes sociales de carácter violento, como el crimen o las manifestaciones patológicas de agresión, que no afectan a la autoridad, o ataques esporádicos a representantes del gobierno, de dimensiones demasiado pequeñas como para alterar el ordenamiento institucional o el ejercicio de la autoridad. Sin embargo, la guerra interna es una categoría analítica poco utilizada por los científicos sociales europeos, dada su escasa operatividad, ya que engloba, sin mayores distinciones, un cú-

18 Harry ECKSTEIN, «Introduction: Toward the Theoretical Study of Internal War», en Harry ECKSTEIN (ed.), Internal War: Problems and Approaches, Londres, Collier-MacMillan y Nueva York, The Free Press, 1964, p. 1, nota; «On the Etiology of Internal Wars», History and Theory (Middletown, CT), vol. IV, nº 2, 1965, p. 133 y The Study of Internal Wars, Princeton, Princeton University Press, 1969.

19 Andrew C. JANOS, «Authority and Violence: The Political Framework of Internal War», en ECKSTEIN, Internal War, p. 130. 
mulo muy diverso de situaciones violentas, que van desde las formas más sangrientas (guerras civiles, grandes revoluciones, genocidios) hasta los golpes de Estado, los asesinatos políticos esporádicos o las huelgas insurreccionales. Esta definición tan imprecisa aísla un medio particular - la violencia - de los fines políticos a los que va dirigida.

Estas consideraciones nos conducen a presumir que no existe un solo arquetipo de guerra civil, ni en su origen ni en su desarrollo, aunque la mayor parte se deben a fracturas de la identidad nacional (de tipo étnico, cultural, religioso, nacionalista, etc.), a la pérdida grave de legitimidad del sistema político o al desmoronamiento del Estado. La guerra civil puede proceder de una insurrección urbana (como el «bogotazo» de abril de 1948 que sucedió al asesinato del líder izquierdista Jorge Eliecer Gaitán), del fracaso de un golpe de Estado militar (el de julio de 1936 en España), de una insurrección popular fallida contra el gobierno (la guerra civil griega de 1946 o la irlandesa de 1926), de la lucha revolucionaria contra el Estado (el actual conflicto colombiano), de un desarrollo revolucionario descontrolado (la revolución mexicana), de una movilización contrarrevolucionaria con o sin apoyo foráneo (la Vendée, las guerras carlistas, la guerra civil rusa o la revuelta cristera mexicana), de un proceso de secesión (guera civil americana) o de la reacción liberadora frente a una intervención militar y/o política extranjera con apoyo autóctono (las guerras partisanas en Italia y Yugoslavia durante la etapa final de la Segunda Guerra Mundial). En definitiva, las guerras civiles suelen comenzar con un acto de sublevación contra el poder estatal que degenera en escalada por los mutuos excesos violentos. Su desarrollo puede adoptar desde la fisonomía de una guerra convencional (el caso del conflicto secesionista americano de 1862-65 o la guerra civil española de 1936-39) hasta la de un conflicto colectivo sin referencia directa o reconocible de forma inmediata con el Estado (las masacres étnicas de los años noventa en la región africana de los Grandes Lagos).

Una sociedad abocada a la guerra civil tiene, según la coyuntura histórica en que se encuentre y la correlación de fuerzas dirigidas al enfrentamiento, multitud de variantes violentas destinadas al derrocamiento del régimen o del sistema vigente. La guerra civil suele convivir con otros tipos de violencia extensiva, como el terrorismo a gran escala, la guerra de guerrillas, el golpe de Estado o la insurrección, aunque de esta última se diferencia en que es un conflicto de tipo horizontal, entre entidades político-militares equiparables, mientras que la insurrección es una violencia de carácter vertical contra la autoridad establecida, mantenida por un grupo disidente más o menos organizado, pero que aún no ha sido capaz de plasmar territorial e institucionalmente su vocación de poder alternativo. Una rebelión contra una autoridad adquiere el carácter legal de guerra (en este caso, de guerra interna) cuando el bando rebelde consigue establecer una estructura político-legal que respalda el poder soberano que pretende. Insurrección y guerra civil suelen ser manifestaciones violentas sucesivas, pero mutuamente excluyentes, de un alzamiento o de un levantamiento de masas contra el régimen instituido. La mayor parte de los conflictos armados nacionales son de naturaleza asimétrica, ya que enfrentan a fuerzas gubernamentales con grupos, movimientos o individuos; a clases gobernantes contra clases subalternas, o a grupos étnicos dominantes contra grupos étnicos dominados. Todo ello provoca un gran debate entre los observadores, que se ven forzados a contemplar el proceso bélico desde un lado u otro de la trinchera dialéctica entre legalidad y subversión ${ }^{20}$.

Las guerras civiles se caracterizan por la profundidad y el arraigo de los sentimientos (la necesidad perentoria de optar por un bando para evitar estar entre dos fuegos) y por la fuerza y barbarie con que se lucha ${ }^{21}$. A diferencia del propósito confesado de las acciones militares convencionales (que, según Clausewitz, consisten en desarmar al enemigo mediante el uso

20 KÖHLER, «Aproximaciones al estudio de las causas de la guerra», pp. 111-112.

21 Leslie MCFARLANE, La violencia y el Estado, Madrid, Eds. Felmar, 1977, pp. 162-165. 
de la fuerza para imponer la propia voluntad), la guerra civil es un tipo de violencia total entre segmentos de una misma población, que persigue como objetivo prioritario el aniquilamiento o sometimiento sin condiciones del adversario, el derrocamiento del régimen imperante o la disolución de un Estado 22 . Como advierte Huntington, «la guerra insurreccional es casi siempre total. Ningún bando busca reconocer la legitimidad del otro, o las negociaciones y acuerdos que implican ese reconocimiento. Los armisticios y los tratados de paz son posibles entre gobiernos, pero raramente entre gobiernos y anti-gobiernos» ${ }^{23}$. La guerra civil se diferencia de la guerra internacional en que no es un enfrentamiento entre Estados independientes, y en su voluntad de extinción del gobierno enemigo y de recomposición de la homogeneidad social e institucional perdidas durante el conflicto.

Charles Zorgbibe caracteriza la guerra civil clásica como un conflicto interno con incidencias internacionales limitadas e indirectas. Los insurrectos eran tratados como criminales a quienes se aplicaba las leyes penales o regímenes de excepción semejantes a los que se ponían en vigor en caso de guerra internacional. Si la guerra civil se extendía fuera del marco jurisdiccional del Estado (por ejemplo, en el mar), se corría el riesgo de que la conflagración se ampliase hasta los confines de las soberanías y se internacionalizase. Si el gobierno legal era impotente para detener la insurrección, podía verse obligado a constatar que la guerra existía de hecho, y reconocer de forma implícita o explícita a los insurrectos como beligerantes, y por lo tanto como entes legales susceptibles de serles aplicadas las leyes de guerra. Así, desde un punto de vista jurídico, se asimilaría el conflicto civil a la guerra internacional, lo que no implicaba que los derrotados no pudieran luego ser sancionados con arreglo al derecho penal nacional. Si la guerra civil ampliaba sus proporciones, terceros Estados podían reconocer bajo ciertas condiciones a los insurrectos como beligerantes, y verse obligados a adoptar una actitud oficial de neutralidad.

En una guerra civil convencional, dos Estados cristalizan en el mismo territorio, cada uno con su propia burocracia y aparato militar, y cada uno reclama la fidelidad del conjunto. Es decir, dos o más gobiernos contienden por la soberanía sobre el pueblo y el territorio. La guerra civil es, pues, la culminación de la estrategia subversiva del «doble poder», que precisa de varios elementos: la existencia de minorías organizadas que preparen la situación bélica con disturbios y elaboren una ideología de la rebeldía y de la justificación de la violencia; la constitución de un instrumento complejo y poderoso de coerción (por ejemplo, una milicia o un ejército revolucionario, que ya han debido tener un papel destacado en las agitaciones y violencias del período prerrevolucionario) que esté en condiciones de competir en pie de igualdad con los mecanismos represivos del régimen, y el establecimiento en parte del territorio de un verdadero contrapoder alternativo que cuente con un apoyo popular, institucional e internacional equiparables al del gobierno instituido. En suma, la guerra civil puede darse por iniciada cuando los rebeldes obtienen de facto el control sobre una parte del territorio, y organizan un gobierno, un aparato militar y una burocracia, es decir, un Estado paralelo. Por contra, los «paraestados» (mafias, milicias, órdenes, sectas) nunca podrán orquestar una guerra civil abierta, ya que no controlan efectivamente ningún tipo de territorio, que es la facultad esencial de la soberanía y del derecho de beligerancia según el ordenamiento legal internacional.

Sin embargo, estos rasgos convencionales se han ido desdibujando en los conflictos civiles de los últimos años. Según Waldmann, la guerra civil ha ido perdiendo su carácter «clásico» para adoptar rasgos pre o extraestatales, como la inobservancia de las reglas (las guerras civiles actuales no conocen ninguna limitación de derecho y se llevan hasta el extremo de la

22 Charles TiLly, From Mobilization to Revolution, Nueva York, Random House-McGraw-Hill Publishing Co./Reading (Mass.), Addison Wesley Publishing Co., 1978, p. 198.

23 Samuel P. Huntington, «Patterns of Violence in World Politics», en Samuel P. Huntington (ed.), Changing Patterns of Military Politics, Glencoe, The Free Press, 1962, p. 21. 
anomia) y el cambio en la motivación y actitud de los combatientes. Ello se percibe, por ejemplo en la proliferación de actitudes privatizadoras (conflicto intenso entre los bandos, pérdida de la importancia de la población como sostén social, empleo de la violencia con fines particulares, como el robo o la venganza, borrando los límites entre violencia política y crimen común) y de socavamiento del poder estatal (multiplicación de «señores de la guerra», con la consiguiente división del territorio y del poder entre las diversas facciones en lucha), además del rechazo de la tradicional separación entre el soldado y la población civil, ya intuida en las guerras populares del siglo $\mathrm{XIX}^{24}$. No es que las guerras civiles sean especialmente cruentas, sino que la crueldad de toda guerra se percibe de forma más intensa por la cercanía espacial o anímica entre los contendientes. Las guerras civiles no son guerras de conquista, sino que se pone en juego la existencia de los grupos contrincantes, su identidad colectiva, e incluso su supervivencia física.

$\mathrm{Al}$ contrario que en las conflagraciones interestatales, las guerras civiles raramente acaban con la negociación y el compromiso, desde el momento en que lo que se dirime es el control del Estado o la identidad nacional y/o comunitaria. Sólo en los conflictos en que los insurgentes logran desgarrar una parte de todo, el compromiso es posible. Las guerras civiles pueden finalizar con la subyugación de una facción sobre otra (como ocurrió en los enfrentamientos civiles norteamericano o español), la obtención de la independencia territorial (como la separación de Bélgica de los Países Bajos en 1830, o la emancipación irlandesa del dominio británico tras la Primera Guerra Mundial), o un agotamiento mutuo que obliga a concertar una tregua que da lugar a nuevas expectativas (como las guerras de Corea, Vietnam o el Líbano). También es frecuente la implicación de poderes extranjeros, que reconocen la beligerancia o la independencia de los contendientes y pueden llevar a una internacionalización la guerra civil, como sucedió con las intervenciones norteamericanas en favor de los insurrectos cubanos contra el dominio español (1898) o incitando la separación de Panamá de Colombia (1903). La mayor parte de los conflictos armados internos de carácter agudo tienen fuertes conexiones internacionales. En opinión de Zorgbibe, la guerra civil moderna aparece como un simple reflejo interno de conflictos internacionales generales, como fue la lucha entre liberalismo y absolutismo durante las guerras carlistas, o las intervenciones defensivas de las grandes potencias en apoyo de regímenes políticos afines con la excusa de evitar precisamente una guerra civil, como sucedió, por ejemplo, con el desembarco de $m a-$ rines norteamericanos en Santo Domingo en abril de 1965 o con la intervención soviética en Hungría en octubre-noviembre de 1956. Para Karl W. Deutsch, los efectos de una intervención exterior en una guerra civil son complejos, ya que pueden ayudar al éxito de la facción a cuyo lado se encuentra si dicha facción está más alienada respecto de su adversario doméstico que de su aliado exterior ${ }^{25}$. El triunfo de alguno de los bandos contendientes en este tipo de conflictos posibilita la culminación de un proceso revolucionario o contrarrevolucionario que ha ido desplegándose en paralelo a las operaciones militares, y que en muy contadas ocasiones deja incólume el sistema político-social previo a la crisis, aunque a la larga tampoco se descarta una absorción parcial del bando derrotado en un régimen convenientemente reformado.

En definitiva, como arquetipo máximo de la violencia instalada en el seno de una comunidad política, la guerra civil ha de ser analizada como una estrategia de alto coste dirigida a obtener resultados máximos, se llamen éstos conquista del poder, revolución, contrarrevolución o eliminación del adversario. Aunque la lectura de sus orígenes, desarrollo y objetivos ha de ser eminentemente política, tampoco se ha de minusvalorar el análisis de otros tipos de

24 Peter WALDMANN, «Guerra civil: aproximación a un concepto difícil de formular», en WALDMANN y REINARES, Sociedades en guerra civil, pp. 27-44.

25 Karl W. DEUTSCH, «External Involvement in Internal War», en ECKSTEIN, Internal War, p. 109. 
manifestaciones que en absoluto resultan colaterales, como la confrontacion de estrategias bélicas, las implicaciones de orden jurídico y estratégico y las repercusiones de estos conflictos internos en la escena internacional.

EduARdo GonZÁlez CALleJA

Instituto de Historia, CSIC 